\title{
Treatment of maple syrup urine disease with high flow hemodialysis in a neonate
}

\author{
Fatih Aygün ${ }^{1}$, Ertuğrul Kıykım² ${ }^{2}$ Çiğdem Aktuğlu-Zeybek ${ }^{2}$, Tanyel Zubarioğlu ${ }^{2}$, Halit Cam ${ }^{1}$ \\ Divisions of ${ }^{1}$ Pediatric Intensive Care and ${ }^{2}$ Nutrition and Metabolism, Department of Pediatrics, Istanbul University, \\ Cerrahpasa Faculty of Medicine, Istanbul, Turkey. E-mail: faygun9@hotmail.com \\ Received: 19th September 2017, Revised: 12th December 2017, 30th December 2017, Accepted: 3rd \\ January 2018
}

SUMMARY: Aygün F, Kıykım E, Aktuğlu-Zeybek Ç, Zubarioğlu T, Cam H. Treatment of maple syrup urine disease with high flow hemodialysis in a neonate. Turk J Pediatr 2019; 61: 107-110.

Continious renal replacement therapy (CRRT) is a well recognizied treatment of choice in acute renal failure, however CRRT became a preferred treatment of metabolic emergencies with high leucine and ammonia levels like Maple syrup urine disease (MSUD). MSUD is a rare metabolic disorder caused by deficiency in the activity of the branched-chain a-ketoacid dehydrogenase complex. The toxic accumulation of branched chain amino acids during acute metabolic decompensation is associated with the appearance of permanent neurological symptoms. Four patients were admitted to our pediatric intensive care department with complains of poor feeding, vomitting, irratibility and coma. Physical examination of the neonates were similar having stupor, hypotonia and depressed newborn reflexes. The leucine levels were between 930-4400 $\mu \mathrm{mol} / \mathrm{L}$. The diagnosis of MSUD was confirmed in all four. They were treated successfully with high flow CRRT having the rates were between $4120 \mathrm{ml} / \mathrm{h} / 1.73 \mathrm{~m} 2$ and $9830 \mathrm{ml} / \mathrm{h} / 1.73 \mathrm{~m} 2$. Early treatment is essential to prevent neurotoxicity and death. CRRT is a choice of treatment in metabolic crisis of MSUD. Herein, we report the successful treatment of acute metabolic decompensation of MSUD with CRRT in 4 neonates.

Key words: mapple syrup urine disease, continuous renal replacement therapy, neonate, leucine.

Maple syrup urine disease (MSUD) is an inborn deficiency of branched chain aminoacids caused by a defect in ketoacid dehydrogenase complex. Infants with classic MSUD, the most severe form, present within the first few days of life with irritability, poor feeding, lethargy, intermittent apnea, opisthotonus, abnormal movements, coma, and encephalopathy. The toxic accumulation of branched chain amino acids, mostly leucine, is associated with the appearance of neurological symptoms. The long term elevated levels of leucine and its metabolite, a-ketoisocaproic acid, causes disruption of brain development and growth. Early treatment is essential to prevent neurotoxicity and death. ${ }^{1}$ Continuous Renal Replacement Therapy (CRRT) is a choice of treatment in the metabolic crisis of MSUD resistant to conservative treatment modalities including nutritional support ${ }^{2}$. Herein, we report the successful treatment of acute metabolic decompensation of MSUD with CRRT in 4 neonates.

\section{Case Report}

Four patients ( 2 female, 2 male) were admitted to our pediatric intensive care department with complains of poor feeding, vomitting, irratibility and coma. The patients were aged between 5 and 19 days. Their body weights were between 2.600 and 3.500 grams. Two of the patients were children of consanguineous parents and two of them had a sibling diagnosed with MSUD (Table I). Physical examination of neonates were similar having stupor, hypotonia and depressed newborn reflexes. They had unusual urine odor suspecting inborn error of metabolism. The inflammatory markers were negative. Laboratory analysis of electrolyte, liver and renal function tests were in normal ranges. 


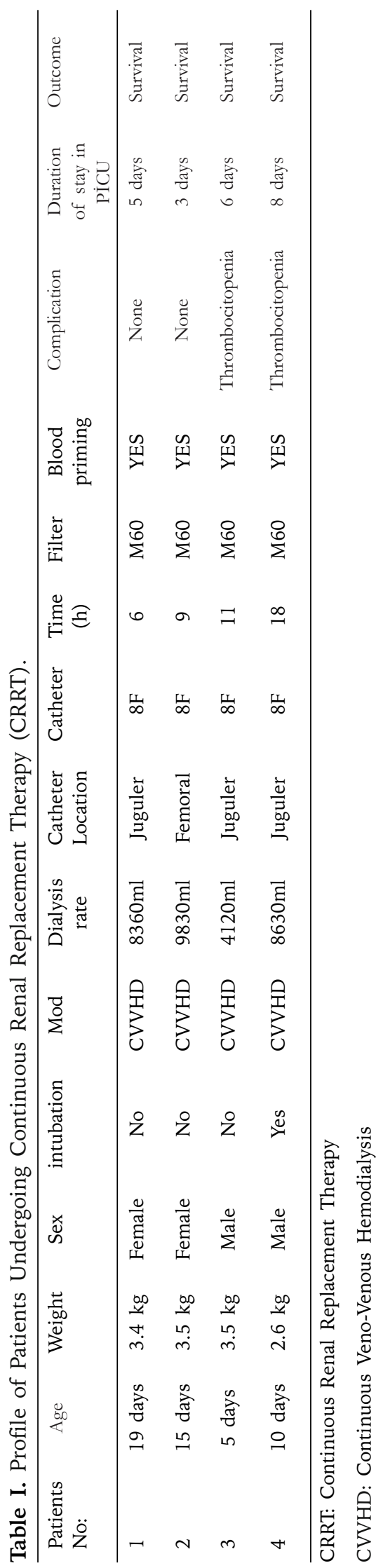

The leucine levels were between 930-4400 $\mu \mathrm{mol} / \mathrm{L}$. The diagnosis of MSUD was confirmed in all four. Hypercaloric parenteral nutrition (110-130 kcal/kg/day) with intravenous high dextrose-containing fluids having a slow insulin infusion $(0.01-0.05 \mathrm{U} / \mathrm{kg} / \mathrm{min})$, intravenous lipid (2-3 g/kg/day) and oral protein/ branched chain aminoacids (BCAA)-free formulas were used as conservative treatment. High flow CRRT was performed, the rates were between $4120 \mathrm{ml} / \mathrm{h} / 1.73 \mathrm{~m}^{2}$ and $9830 \mathrm{ml} / \mathrm{h} / 1.73 \mathrm{~m}^{2}$. The mean duration of CRRT was 11 hours (Table II). We did not have any complication except thrombocytopenia in two patient. One patient needed mechanical ventilation because of poor neurological condition and very high leucine levels $(4400 \mu \mathrm{mol} / \mathrm{L})$.

Written inform consent was received from all of the families.

\section{Discussion}

Maple syrup urine disease is a rare metabolic disorder of autosomal recessive inheritance caused by deficiency in the activity of the branched-chain a-ketoacid dehydrogenase complex. Increased plasma concentration of BCAA, mainly leucine is associated with neurological symptoms and neonatal encephalopathy. Conservative treatment of MSUD consists of dietary restriction of BCAA by low protein intake with supplementation of thiamine, valine, isoleucine and providing sufficient calories to prevent catabolism. ${ }^{1}$ In case of life threatening acute metabolic crisis, plasma concentration of toxic metabolites should be reduced as soon as possible. Renal replacement treatment modalities are highly effective in the management of acute metabolic crisis of MSUD ${ }^{3}$. Peritoneal dialysis (PD) was one of preferred treatment regimen for BCAA clearence in the last decade ${ }^{4}$. However, the renal clearance, solute and liquid removal capacity of PD is limited. Intermittent hemodialysis (IHD) can also achieve rapid removal of BCAA, Phan et al. ${ }^{5}$ demonstrated the efficiency of IHD in acute crisis of MSUD in children older 1 year old. But, IHD can cause hemodynamic instability and can increase the degree of neurologic damage by a decrease in arterial blood pressure and cerebral blood flow ${ }^{6}$. Newborns are more susceptible to this side effect. Also, if the catabolic state of the 
Table II. Leucine Levels in MSUD Patients.

\begin{tabular}{lcccc}
\hline Variables & Case-1 & Case-2 & Case-3 & Case-4 \\
\hline 0-hours & $930 \mu \mathrm{mol} / \mathrm{L}$ & $2020 \mu \mathrm{mol} / \mathrm{L}$ & $1071 \mu \mathrm{mol} / \mathrm{L}$ & $4400 \mu \mathrm{mol} / \mathrm{L}$ \\
6-hours & - & $886 \mu \mathrm{mol} / \mathrm{L}$ & $285 \mu \mathrm{mol} / \mathrm{L}$ & $2100 \mu \mathrm{mol} / \mathrm{L}$ \\
CRRT was stopped & $214 \mu \mathrm{mol} / \mathrm{L}$ & $225 \mu \mathrm{mol} / \mathrm{L}$ & $18 \mu \mathrm{mol} / \mathrm{L}$ & $600 \mu \mathrm{mol} / \mathrm{L}$ \\
Leucine reduction & $12.8 \%$ & $9.9 \%$ & $5.5 \%$ & $7.2 \%$ \\
rate $\%$ per hour & $91 \%$ & $89 \%$ & $98.3 \%$ & $86.4 \%$ \\
Leucine reduction rate & 6 & 9 & 18 & 12 \\
Time (hours) & 8360 & 9830 & 4120 & 8630 \\
Dialysis rate (ml/h/1.73) & & & & \\
\hline
\end{tabular}

CRRT: Continious Renal Replacement Therapy

MSUD: Maple syrup urine disease

patient continues at the end of dialysis, the leucine levels continue to increase due to the rebound effect of IHD. CRRT may not lead to this rebound phenomenon because of longer duration. We preferred CRRT because our patients were neonates aged between 5-19 days and had the risk of hemodynamic instability. Blood pressures of our patients remained stable with CRRT.

In 1999, Schaefer et al. ${ }^{7}$ reported that both PD and IHD were less effective and more dangerous than CRRT. Although, CRRT is a well established treatment modality for patients with renal disorders such as acute kidney insufficiency, it became a preferred modality of treatment of several non renal-indications like metabolic emergencies with high ammonia and leucine levels. Sutherland et al. ${ }^{8}$ reported the utilization rate of CRRT in metabolic disease of newborn as $4 \%$. In an other report, Askenazi et al. ${ }^{9}$ reported the metabolic disorder prevalence in patients under $10 \mathrm{~kg}$ who received CRRT as $15 \%$.

We used high flow Continuous Veno-Venous Hemodialysis and rapidly reduced the most toxic amino acid, leucine (Table II). Our leucine removal rate was faster than other cases reported in literature and the total removal time of CRRT was shorter. ${ }^{10}$ The rapid removal of leucine does not cause a problem because, leucine is not an osmotic molecule and it is known that its quick clearance from the serum will not increase cerebral edema on its own, as the brain blood flow is constant. ${ }^{5}$

The management of CRRT can be difficult in newborn. The most important issue in CRRT for children is the canulation of catheters. For our cases catheters were attached by a single specialist using the Seldinger method without any complications.

In conclusion, we aimed to show that CRRT is an efficient treatment method that can be used in the acute metabolic crisis of MSUD combined with nutritional support. Continuous hemodiafiltration rapidly and safely clears BCAAs and limits length of time that the patient's exposed to neurotoxic levels. However, we believe that more extensive studies that contain more supporting facts are needed.

\section{REFERENCES}

1. Zinnanti WJ, Lazovic J, Griffin K, et al. Dual mechanism of brain injury and novel treatment strategy in maple syrup urine disease. Brain 2009; 132: 903-918.

2. Lai YC, Huang HP, Tsai IJ, Tsau YK. High-volume continuous venovenous hemofiltration as an effective therapy for acute management of inborn errors of metabolism in young children. Blood Purif 2007; 25: 303-308.

3. Gouyon JB, Desgres J, Mousson C. Removal of branchedchain amino acids by peritoneal dialysis, continuous arteriovenous hemofiltration, and continuous arteriovenous hemodialysis in rabbits: implications for maple syrup urine disease treatment. Pediatr Res 1994; 35: 357-361.

4. Wendel U, Becker K, Przyrembel H, et al. Peritoneal dialysis in maple-syrup urine disease: studies on branched-chain amino and keto acids. Eur J Pediatr 1980; 134: 57-63.

5. Phan V, Clermont MJ, Merouani A, et al. Duration of extracorporeal therapy in acute maple syrup urine disease: a kinetic model. Pediatr Nephrol 2006; 21 : 698-704. 
6. Sadowski RH, Harmon WE, Jabs. Acute hemodialysis of infants weighing less than five kilograms. Kidney Int 1994; 45: 903-906.

7. Schaefer F, Straube E, Oh J, Mehls O, Mayatepek E. Dialysis in neonates with inborn errors of metabolism. Nephrol Dial Transplant 1999; 14: 910-918.

8. Sutherland SM, Alexander SR. Continuous renal replacement therapy in children. Pediatr Nephrol 2012; 27: 2007-2016.
9. Askenazi DJ, Goldstein SL, Koralkar R, et al. Continuous renal replacement therapy for children $\leq 10$ kg: a report from the prospective pediatric continuous renal replacement therapy registry. J Pediatr 2013; 162: 587-592.

10. Demirkol D, Şık G, Topal N, et al. Continuous Venovenous Hemodiafiltration in the Treatment of Maple Syrup Urine Disease. Blood Purif 2016; 42: 27-32. 